\title{
Polymorphisms in promoter regions of IL-6 and IL-10 genes in breast cancer: a case-control study
}

\author{
E.S. AISuhaibani ${ }^{1}$, N.A. Kizilbash ${ }^{2}$, S. Malik ${ }^{3}$, J.I. Dasti ${ }^{4}$, F. Al Beladi ${ }^{5}$ and \\ N. El-Morshedi ${ }^{6}$
}

'Department of Zoology, College of Science, King Saud University, Riyadh, Saudi Arabia

2Department of Medical Laboratory Technology, Faculty of Applied Medical Sciences, Northern Border University, Arar, Saudi Arabia

${ }^{3}$ Department of Animal Sciences, Faculty of Biological Sciences,

Quaid-i-Azam University, Islamabad, Pakistan

${ }^{4}$ Department of Microbiology, Faculty of Biological Sciences, Quaid-i-Azam University, Islamabad, Pakistan

${ }^{5}$ Department of Internal Medicine, Faculty of Medicine, King Abdulaziz University, Jeddah, Saudi Arabia

${ }^{6}$ Department of Zoology, Faculty of Science, Mansoura University, Mansoura, Egypt

Corresponding authors: N.A. Kizilbash / S. Malik

E-mail: fsd707@gmail.com / malik@qau.edu.pk

Genet. Mol. Res. 15 (1): gmr.15017360

Received August 4, 2015

Accepted November 13, 2015

Published March 24, 2016

DOI http://dx.doi.org/10.4238/gmr.15017360

ABSTRACT. Polymorphisms in interleukin genes (IL-6 and $I L-10)$ are involved in the pathogenesis of breast cancer. This study investigated polymorphisms in the promoter regions of IL-6 (-174G/C) and IL-10 $(-1082 \mathrm{G} / \mathrm{A})$ through a case-control study employing 80 female subjects who were pathologically diagnosed with breast cancer. All patients received follow-up care at the Mansoura University Hospital, Mansoura, Egypt. We included another 80 females (controls) from the same population, showing no signs of malignancy. Clinicopathological features were examined in the 
patient groups, including the expression of estrogen and progesterone receptors, involvement of the lymph node, tumor morphology, and tumor grades. Genotyping of the promoter polymorphisms was performed using allele-specific polymerase chain reaction method. There was a significant decrease in the mean age of menarche in the patient group than that in the normal individuals. For the $I L-6-174 \mathrm{G} / \mathrm{C}$ polymorphism, there was a significantly higher frequency of the CC genotype in the patients than that in the controls (odds ratio $=5.49$ ). Furthermore, the CC genotype was significantly more prevalent among the patients who had lymph node involvement. For the $I L-10-1082 \mathrm{G} / \mathrm{A}$ polymorphism, there was no difference in the distribution of genotypes among the patients and the control subjects. However, the tumor size was significantly larger in patients who were harboring the $A A$ genotype than that in the patients who had $A G$ or GG genotypes.

Key words: Interleukin; IL-6; IL-10; Promoter polymorphisms; Allele specific PCR; Breast cancer

\section{INTRODUCTION}

Breast cancer is one of the most common causes of morbidity and it severely affects the general health and life expectancy of women. The incidence of breast cancer has increased to an alarming level in certain developed and developing countries (Kamangar et al., 2006; Jemal et al., 2010). The etiological factors and pathogenesis of this disease are highly complex. In addition to numerous other mechanisms, involvement of cytokines in the progression and pathogenesis of cancer has been observed in various patient cohorts (Smyth et al., 2004; Pooja et al., 2012). For instance, the cytokines interleukin (IL)-1, IL-4, IL-6, and IL-10 are important biomarkers for breast cancer pathogenesis and prognosis (Hefler et al., 2005).

IL-6 is involved in various vital cellular functions such as the inflammatory response, carcinogenesis and bone metabolism (Diehl and Rincon, 2002). In breast cancer patients, the amount of circulating IL- 6 has been found to be higher than in their healthy counterparts. The amount of circulating IL- 6 correlates with the severity of cancer. Furthermore, IL- 6 has a likely role in the intercellular signaling between breast cancer epithelium and mesenchyme. It is also associated with the density of estrogen and progesterone receptors in these cells (Bozcuk et al., 2004). The transcription of IL-6 is modulated by a promoter region of 303 base pairs and the $-174 \mathrm{G} /$ $\mathrm{C}$ polymorphism in the promoter sequence has been shown to be associated with pathological and clinical variables of breast cancer. This polymorphism influences in vivo expression of the gene by reducing its transcription rate and is associated with an improved therapeutic outcome in high-risk breast cancer individuals (Vickers et al., 2002; DeMichele et al., 2003).

Another breast cancer biomarker, IL-10, is an important immune-regulatory cytokine and can potentially suppress as well as stimulate the inflammatory and immune responses (Mocellin et al., 2004; Pooja et al., 2012). IL-10 has been shown to be overexpressed in breast cancer tumors (Venetsanakos et al., 1997). Studies have revealed that IL-10 may affect the clinical course of cancer types and the pathogenesis of breast cancer (Howell and Rose-Zerilli, 2007). A polymorphism in the promoter region of $I L-10,-1082 \mathrm{G} / \mathrm{A}$, modulates its transcriptional landscape 
and thus influences the susceptibility and pathogenesis of breast cancer (Gibson et al., 2001; Hua et al., 2013).

Nationally representative studies on the prevalence and incidence of cancer in Egypt are scarce (Ibrahim et al., 2014). Few sporadic reports present hospital-based registries that cannot depict the overall burden of cancer in a country (Abou-Zeid et al., 2006). Recent reports have shown that breast cancer is one of the most common cancer types in the country, succeeded only by liver cancer (Ibrahim et al., 2014). Curiously, different biomarkers associated with certain cancer types have not been studied in Egyptian cancer patients. This case-control study investigated polymorphisms in promoter regions of $I L-6(-176 \mathrm{G} / \mathrm{C})$ and $I L-10(-1082 \mathrm{G} / \mathrm{A})$ in the Egyptian population, and evaluated whether certain genotypes at these loci are associated with breast cancer pathogenesis and clinical manifestations of cancer.

\section{MATERIAL AND METHODS}

\section{Case-control study}

The patients included 80 female individuals who were pathologically diagnosed with breast cancer and received follow-up care at Mansoura University Hospital, Mansoura (Egypt). After confirmed histopathological diagnosis, the patients were treated by conservative surgery with axillary dissection or modified radical mastectomy depending on the tumor size and nuclear grading. The healthy control individuals $(N=80)$ were recruited from women who were clinically free from any malignancy or breast masses and were patients at the General Surgery Department, Mansoura University Hospital (Egypt) for minor surgical operations unrelated to oncology or endocrinology. The Institutional Ethical Committee approved this study and written informed consent was obtained from all patients and controls prior to the recruitment. Demographic information including the age of menarche and menopause was acquired.

\section{Clinicopathological investigations and immunohistochemistry}

Clinicopathological features of the patient group were observed, including expression of estrogen receptor (ER), progesterone receptor (PR), involvement of the lymph node (LN), tumor size/morphology, and tumor grade. Immunohistochemistry was performed with avidin biotin complex utilizing 3, 3'-diaminobenzidine (DAB) chromogen (Dako, Glostrup, Denmark). Monoclonal mouse anti-human ER (anti-ER; 1D5, Dako) and PR (anti-PR; PgR 636, Dako) were used for the detection of receptors. Standard immunoperoxidase kits were purchased from Dako. The reagents used in the detection system includes: protein blocking agent, biotinylated secondary antibody, substrate chromogen mixture (DAB), Meyer's hematoxylin solution, streptavidin-peroxidase reagent, and mounting medium. Reagents not provided in the kits were: reagent for antigen retrieval (citrate buffer solution), working buffer solution, phosphate buffered saline, and $0.3 \%$ hydrogen peroxide in methanol.

Estrogen and progesterone receptors were categorized by positive brown nuclear staining by the method of Allred et al. (1998). This method depends on the summation of proportion score (percent of nuclear staining: 1-5) and intensity score (intensity of staining: 1-3). The summation score ranged from 1 to 8 . Scores under 2 were considered negative while scores from 3 to 8 were considered positive. 


\section{DNA extraction and genotyping}

Peripheral blood samples were collected in polyethylene tubes containing EDTA and were stored at $-30^{\circ} \mathrm{C}$. DNA was isolated with a genomic DNA purification kit (Genta Genomic Kit; Genta Systems, Minneapolis, MN, USA). Promoter polymorphisms in IL-6 (IL-6 -174G/C; rs1800795) and IL-10 (IL-10 -1082G/A; rs1800896) were investigated using the allele-specific polymerase chain reaction (PCR) amplification protocol (primer sequences are shown in Table 1). PCR was performed with 300 ng DNA, $500 \mathrm{nM}$ each primer, $200 \mathrm{mM}$ each dNTP, and $2.5 \mathrm{U}$ Taq polymerase (Amplitaq Gold; Perkin Elmer Cetus, Norwalk, CT, USA). For the amplification of the IL-6 polymorphism, the PCR conditions were as previously described (Cavet et al., 1999; Cavet et al., 2001). PCR was carried out using 30 cycles of: $94^{\circ} \mathrm{C}$ for $30 \mathrm{~s}, 54^{\circ} \mathrm{C}$ for $60 \mathrm{~s}$, and $72^{\circ} \mathrm{C}$ for $60 \mathrm{~s}$, followed by a final extension at $72^{\circ} \mathrm{C}$ for $7 \mathrm{~min}$. Amplification of the $I L-10$ polymorphism was carried out using 30 cycles of: $94^{\circ} \mathrm{C}$ for $30 \mathrm{~s}, 60^{\circ} \mathrm{C}$ for $60 \mathrm{~s}$, and $72^{\circ} \mathrm{C}$ for $60 \mathrm{~s}$, followed by a final extension at $72^{\circ} \mathrm{C}$ for 6 min. The amplification yields were resolved on a $3 \%$ agarose gel, which was stained with ethidium bromide and visualized under UV light.

Table 1. Primer sequences used to characterize SNPS.
\begin{tabular}{l|l|l|l|c}
\hline Polymorphism & Primers & Primer sequence $\left(5{ }^{\prime}-3^{\prime}\right)$ & Nucleotide specificity & Product size (bp) \\
\hline \multirow{3}{*}{$L-6-174 G / C$} & Forward (F) & GAGCTTCTCTTTCGTTCC & & 234 \\
\cline { 2 - 5 } & Reverse (R1) & CCCTAGTTGTGTCTTGCC & Specific for G & \\
\cline { 2 - 4 } & Reverse (R2) & CCCTAGTTGTGTCTTGCG & Specific for C & \\
\hline \multirow{2}{*}{$I L-10-1082 G / A$} & Forward (F) & AGCAACACTCCTCGTCGCAAC & & 179 \\
\cline { 2 - 4 } & Reverse (R1) & CCTATCCCTACTTCCCCC & Specific for G & \\
\cline { 2 - 4 } & Reverse (R2) & CCTATCCCTACTTCCCCT & Specific for A & \\
\hline
\end{tabular}

\section{Statistical analysis}

Data were recorded and maintained as Microsoft Excel files and analyzed using SPSS17.0 (Chicago, IL, USA). The chi-square test $\left(\chi^{2}\right)$ was used for comparison between groups. The Student $t$-test was used for quantitative data (mean \pm standard deviation) to compare variables in the patient group against the control group. A level of significance set at a probability of $5 \%(P<0.05)$.

\section{RESULTS}

A total of 80 cancer patients and 80 control individuals were recruited in this study. The characteristics of the patients and controls regarding the mean age at menarche and menopausal status are summarized in Table 2 . The mean age at menarche in the patient group was significantly lower compared to the controls (12.3 vs 13.1 years, respectively; $\mathrm{P}=0.02$; Table 2 ). However, there was no difference in the menopausal status between the two groups.

Table 2. Demographic characteristics of patients and healthy controls.

\begin{tabular}{l|c|c|c}
\hline Variable & Breast cancer patients (N = 80) & Controls (N = 80) & P value \\
\hline Age at menarche (years) & $12.3 \pm 2.1$ & $13.1 \pm 2.3$ & $0.02^{*}$ \\
\hline Menopausal status & 24 & 27 & 0.73 \\
\hline Premenopausal & 56 & 53 & 0.83 \\
\hline Postmenopausal & \multicolumn{3}{|c}{} \\
\hline
\end{tabular}

*Distribution was statistically significant (at a cut off values of $P<0.05$ ). 
For the IL-6 -174G/C polymorphism, there was a significantly higher frequency of the CC genotype in the patients with breast cancer compared to the controls $[P<0.001$; odds radio (OR) = 5.49] (Table 3 and Figure 1). Also, there was a significant association of the $C$ allele with the patient group than that with the control group $(P=0.0003)$. Furthermore, for the $I L-10-1082 \mathrm{G} / \mathrm{A}$ polymorphism, there was no difference in the distribution of genotypes (GG, GA and AA) or $G$ and A alleles among the cancer patients and control individuals $(O R=1.08 ; P=0.91)$ (Table 3 and Figure 2).

The association between the IL-6 -174G/C genotypes (GG, GC, CC) and the clinicopathological features of patients was also examined. No association was observed between any of the three genotypes and the expression of ER and PR, tumor size and the grade of the tumor (Table 4). However, LN involvement was observed to be pronounced in patients with breast cancer who had the CC genotype compared with patients with the GG or GC genotypes $(P=$ 0.018). Likewise, for the IL-10 -1082 G/A polymorphism, genotypes were not associated with the clinical variables of patients, including expression of ER and PR, LN involvement and the grade of the tumor (Table 4). However, the tumor size was significantly higher in the patients who were carriers of the AA genotype compared to the patients with $A G$ or $G G$ genotypes $(P=0.036)$.

Table 3. Genotype frequencies of $I L-6$ and $I L-10$ promoter polymorphisms among the patients and controls.

\begin{tabular}{|c|c|c|c|c|}
\hline Genotype & Cancer patients $(\mathrm{N}=80)$ & Controls $(\mathrm{N}=80)$ & $P$ value & Odds ratio $(95 \% \mathrm{Cl})$ \\
\hline \multicolumn{5}{|l|}{ IL-6 } \\
\hline$-174 \mathrm{G} / \mathrm{G}$ & 14 & 24 & & \\
\hline$-174 \mathrm{G} / \mathrm{C}$ & 34 & 46 & $0.34^{*}$ & $1.27(0.57-2.81)$ \\
\hline$-174 \mathrm{C} / \mathrm{C}$ & 32 & 10 & $0.0004^{* *}$ & $5.49(2.08-14.46)$ \\
\hline$-174 \mathrm{G}$ allele & 62 & 94 & \multirow{2}{*}{0.0003} & \\
\hline -174 C allele & 98 & 66 & & \\
\hline \multicolumn{5}{|l|}{ IL-10 } \\
\hline-1082 G/G & 17 & 16 & & \\
\hline$-1082 \mathrm{G} / \mathrm{A}$ & 47 & 50 & $0.76^{*}$ & $0.88(0.40-1.95)$ \\
\hline$-1082 \mathrm{~A} / \mathrm{A}$ & 16 & 14 & $0.89^{* *}$ & $1.08(0.40-2.90)$ \\
\hline$-1082 \mathrm{G}$ allele & 81 & 82 & \multirow{2}{*}{0.91} & \\
\hline$-1082 \mathrm{~A}$ allele & 79 & 78 & & \\
\hline
\end{tabular}

${ }^{*} \chi^{2}$ test, a heterozygous versus wild-type calculation was performed. ${ }^{*} \chi^{2}$ test, a homozygous versus wild-type calculation was performed.

Table 4. Genotype frequencies of $I L-6$ and $I L-10$ promoter polymorphisms and clinicopathological features of cancer patients.

\begin{tabular}{|c|c|c|c|c|c|c|c|c|c|c|c|c|c|}
\hline \multirow{2}{*}{ Genotypes } & \multirow[t]{2}{*}{ Frequency } & \multicolumn{2}{|c|}{ ER expression } & \multicolumn{2}{|c|}{ PR expression } & \multicolumn{2}{|c|}{ LN involvement } & \multicolumn{3}{|c|}{ Tumor size $(\mathrm{cm})$} & \multicolumn{3}{|c|}{ Tumor grade } \\
\hline & & Yes & No & Yes & No & Yes & No & $<2$ & $2-5$ & $>5$ & I & II & III \\
\hline
\end{tabular}

\begin{tabular}{|c|c|c|c|c|c|c|c|c|c|c|c|c|c|}
\hline \multicolumn{14}{|l|}{ IL-6 } \\
\hline$-174 \mathrm{G} / \mathrm{G}$ & $\mathrm{N}=14$ & 6 & 8 & 9 & 5 & 7 & 7 & 8 & 4 & 2 & 6 & 7 & 1 \\
\hline$-174 \mathrm{G} / \mathrm{C}$ & $\mathrm{N}=34$ & 16 & 18 & 18 & 16 & 17 & 17 & 16 & 12 & 6 & 13 & 18 & 3 \\
\hline$-174 \mathrm{C} / \mathrm{C}$ & $\mathrm{N}=32$ & 21 & 11 & 20 & 12 & 26 & 6 & 16 & 10 & 6 & 11 & 18 & 3 \\
\hline$P$ value & & \multicolumn{2}{|c|}{0.213} & \multicolumn{2}{|c|}{0.658} & \multicolumn{2}{|c|}{$0.018^{*}$} & \multicolumn{3}{|c|}{0.976} & \multicolumn{3}{|c|}{0.988} \\
\hline \multicolumn{14}{|l|}{ IL-10 } \\
\hline$-1028 \mathrm{G} / \mathrm{G}$ & $\mathrm{N}=17$ & 9 & 8 & 8 & 9 & 11 & 6 & 3 & 9 & 5 & 5 & 11 & 1 \\
\hline$-1028 \mathrm{G} / \mathrm{A}$ & $\mathrm{N}=47$ & 25 & 22 & 30 & 17 & 28 & 19 & 26 & 13 & 8 & 18 & 24 & 5 \\
\hline$-1028 \mathrm{~A} / \mathrm{A}$ & $\mathrm{N}=16$ & 9 & 7 & 9 & 7 & 11 & 5 & 11 & 4 & 1 & 7 & 8 & 1 \\
\hline $\mathrm{P}$ value & & \multicolumn{2}{|c|}{0.975} & \multicolumn{2}{|c|}{0.472} & \multicolumn{2}{|c|}{0.789} & \multicolumn{3}{|c|}{$0.036^{*}$} & \multicolumn{3}{|c|}{0.841} \\
\hline Number & & 43 & 37 & 47 & 33 & 50 & 30 & 40 & 26 & 14 & 30 & 43 & 7 \\
\hline
\end{tabular}

*Distribution was statistically significant at a cut off values of $\mathrm{P}<0.05$; $\mathrm{ER}=$ estrogen receptor; $\mathrm{PR}=$ progesterone receptor; LN = lymph node. 

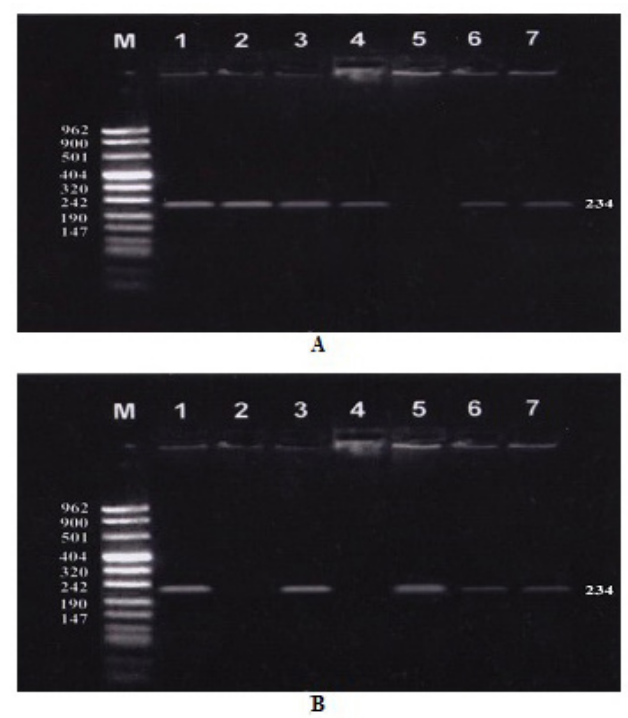

Figure 1. PCR amplification of $I L-6-174(G / C)$ polymorphism. $G$ allele (A) and C allele (B) are shown and the band size is $234 \mathrm{bp}$. Lane $M=\mathrm{DNA}$ molecular weight marker; lanes 1, 3, 6, 7 = positive for $\mathrm{G}$ and $\mathrm{C}$ alleles giving $\mathrm{GC}$ genotype; lanes 2 and 4 = positive for $G$ and negative for $C$ alleles giving $G G$ genotype; and lane $5=$ positive for $C$ and negative for $\mathrm{G}$ allele giving $\mathrm{CC}$ genotype.
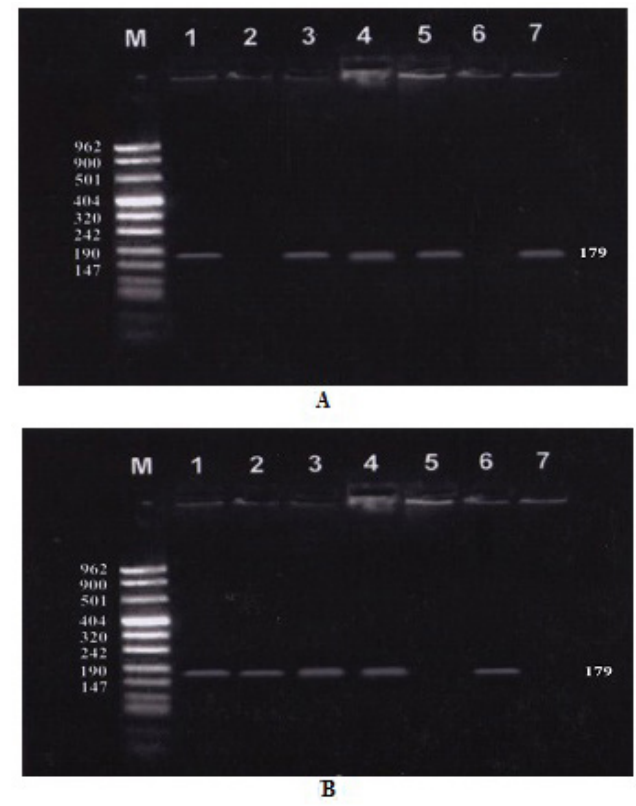

Figure 2. PCR amplification of $I L-10-1082 \mathrm{G} / \mathrm{A}$ polymorphism. $\mathrm{G}$ allele $(\mathrm{A})$ and $A$ allele $(\mathrm{B})$ are shown and the band size is $179 \mathrm{bp}$. Lane $M=\mathrm{DNA}$ molecular weight marker; lanes 1, 3, 4 = positive for $\mathrm{G}$ and A alleles giving GA genotype; lanes 5, 7 = positive for $G$ and negative for $A$ alleles giving $G G$ genotype; and lanes 2, 6 = positive for $A$ and negative for $\mathrm{G}$ alleles giving $\mathrm{AA}$ genotype. 


\section{DISCUSSION}

Molecular and genetics methods are increasingly becoming a part of routine medical diagnostics. PCR-based testing for polymorphisms that predispose individuals to disease has gained considerable interest among researchers and physicians studying and treating chronic diseases like cancer. Hence, the screening for mutations in candidate genes of different types of cancer has been proposed as a powerful tool in predicting the risk of morbidity (Kammerer et al., 2004).

The proinflammatory multifunctional IL-6 is a key cytokine in humoral immune response and involves the activation of B cells (Smith et al., 2004). The IL-6 -174G/C polymorphism has been shown to influence plasma concentrations of the cytokine in response to inflammatory stimuli. Several studies reported significant demographic differences in the distribution of $-174 \mathrm{G} / \mathrm{C}$ alleles, underlying the importance of population-specific references when evaluating the clinical relevance of this polymorphism (Litovkin et al., 2007). The IL-6 -174G/C polymorphism is known to reduce gene transcription rate leading to an inhibition in the growth of tumor cells (Landi et al., 2003). To the best of our knowledge, this is the first report on the IL-6 -174G/C polymorphism in breast cancer in an Egyptian population. Our results showed that the prevalence of the CC genotype was significantly higher among the cancer patients. These findings are consistent with Hefler et al. (2005), who also observed a higher incidence of the CC genotype among Caucasian women with breast cancer.

Racial differences have been observed in the proportion of IL-6 -174 G/C alleles and their contribution to cancer. In a recent study, Yang et al. (2014) performed a meta-analysis based on published data and found no association between this polymorphism and prostate cancer risk in Asian and Caucasian individuals. However, the CC genotype was observed to confer increased risk of cancer among the African-American patients. In agreement with the previous study, Yeh et al. (2010) observed the incidence of colorectal cancer among patients of Taiwanese origin and investigated the association between the $\mathrm{IL}-6-174 \mathrm{G} / \mathrm{C}$ polymorphism, serum IL-6 level, and carcinoembryonic antigen (CEA) level. The prevalence of the $G$ allele was significantly lower in the Taiwanese cohort compared to the western analogs. Furthermore, the average IL- 6 and CEA levels were significantly lower in patients with the $\mathrm{G}$ allele. The authors concluded that ethnicity affected the status of the $I L-6-174 \mathrm{G} / \mathrm{C}$ polymorphism, which consequently influenced the expression of serum IL-6 and CEA and the incidence of synchronous cancers of other origins.

In the present study, the IL-10 -1082 G/A polymorphism was not associated with breast cancer. Previously, Talaat et al. (2014) demonstrated a significant increase in the frequency of the GG genotype in Egyptian patients with Behcet's disease than that in the healthy controls. In a population based study in Northern India, Ahirwar et al. (2009) observed that GA and AA genotypes and A allele carriers of the IL-10 -1082 G/A polymorphism demonstrated an increased risk for urothelial bladder cancer. The authors suggested that the $I L-10-1082 \mathrm{G} / \mathrm{A}$ polymorphism may be used as a molecular marker of urothelial bladder cancer. The $I L-10$ promoter polymorphism $-1082 \mathrm{G} / \mathrm{A}$ was also observed to exhibit a significant difference in the genotype frequency between patients and control group in Taiwanese population (Kuo et al., 2014). Furthermore, patients carrying the $G$ allele were found to have a higher risk for gastric cancer compared to carriers of the A allele.

Li et al. (2014) conducted a meta-analysis study to examine the association between the $I L-10-1082 \mathrm{~A} / \mathrm{G}$ polymorphism and the risk of gastrointestinal cancer. The authors observed that the $\mathrm{G}$ allele significantly increased susceptibility to gastric cancer in an Asian population. In another independent meta-analysis, the IL-10 -1082 A/G polymorphism was associated with risk of type 2 
diabetes mellitus (Hua et al., 2013). In conclusion, the polymorphisms in the promoter regions of IL-6 and IL-10 may be employed as predictors of increased risk or pathogenesis of breast cancer. However, in order to fully understand the association between polymorphisms in candidate genes and breast cancer, other IL genes should also be screened in cancer patients.

\section{Conflicts of interest}

The authors declare no conflict of interest.

\section{ACKNOWLEDGMENTS}

We would like to acknowledge the help and support of the Deanship of Research, Northern Border University, Arar, Saudi Arabia and Mansoura University Hospital, Mansoura, Egypt.

\section{REFERENCES}

Abou-Zeid W, El-Khwsky F, Mokhtar S, Sherif M, et al. (2006). Descriptive epidemiology and multivariate survival analysis of oral and pharyngeal malignancies in Alexandria. J. Med. Res. Inst. 27: 262-270.

Ahirwar D, Mandhani A and Mittal RD (2009). Interleukin-10 G-1082A and C-819T polymorphisms as possible molecular markers of urothelial bladder cancer. Arch. Med. Res. 40: 97-102.http://dx.doi.org/10.1016/j.arcmed.2008.11.006

Allred DC, Harvey JM, Berardo M and Clark GM (1998). Prognostic and predictive factors in breast cancer by immunohistochemical analysis. Mod. Pathol. 11: 155-168.

Bozcuk H, Uslu G, Samur M, Yildiz M, et al. (2004). Tumour necrosis factor-a, interleukin-6, and fasting serum insulin correlate with clinical outcome in metastatic breast cancer patients treated with chemotherapy. Cytokine 27: 58-65.http://dx.doi. org/10.1016/j.cyto.2004.04.002

Cavet J, Middleton PG, Segall M, Noreen H, et al. (1999). Recipient tumor necrosis factor-alpha and interleukin-10 gene polymorphisms associate with early mortality and acute graft-versus-host disease severity in HLA-matched sibling bone marrow transplants. Blood 94: 3941-3946.

Cavet J, Dickinson AM, Norden J, Taylor PR, et al. (2001). Interferon-y and interleukin-6 gene polymorphisms associate with graft-versus-host disease in HLA-matched sibling bone marrow transplantation. Blood 98: 1594-1600.http://dx.doi. org/10.1182/blood.V98.5.1594

DeMichele A, Martin AM, Mick R, Gor P, et al. (2003). Interleukin-6 -174G-->C polymorphism is associated with improved outcome in high-risk breast cancer. Cancer Res. 63: 8051-8056.

Diehl S and Rincón M (2002). The two faces of IL-6 on Th1/Th2 differentiation. Mol. Immunol. 39: 531-536.http://dx.doi. org/10.1016/S0161-5890(02)00210-9

Gibson AW, Edberg JC, Wu J, Westendorp RG, et al. (2001). Novel single nucleotide polymorphisms in the distal IL-10 promoter affect IL-10 production and enhance the risk of systemic lupus erythematosus. J. Immunol. 166: 3915-3922. http://dx.doi.org/10.4049/jimmunol.166.6.3915

Hefler LA, Grimm C, Lantzsch T, Lampe D, et al. (2005). Interleukin-1 and interleukin-6 gene polymorphisms and the risk of breast cancer in caucasian women. Clin. Cancer Res. 11: 5718-5721.http://dx.doi.org/10.1158/1078-0432.CCR-05-0001

Howell WM and Rose-Zerilli MJ (2007). Cytokine gene polymorphisms, cancer susceptibility, and prognosis. J. Nutr. 137 (Suppl): 194S-199S.

Hua Y, Shen J, Song Y, Xing Y, et al. (2013). Interleukin-10 -592C/A, -819C/T and -1082A/G Polymorphisms with Risk of Type 2 Diabetes Mellitus: A HuGE Review and Meta-analysis. PLoS One 8: e66568.http://dx.doi.org/10.1371/journal. pone.0066568

Ibrahim AS, Khaled HM, Mikhail NN, Baraka H, et al. (2014). Cancer incidence in egypt: results of the national populationbased cancer registry program. J. Cancer Epidemiol. 2014: 437971.http://dx.doi.org/10.1155/2014/437971

Jemal A, Center MM, DeSantis C and Ward EM (2010). Global patterns of cancer incidence and mortality rates and trends. Cancer Epidemiol. Biomarkers Prev. 19: 1893-1907.http://dx.doi.org/10.1158/1055-9965.EPI-10-0437

Kamangar F, Dores GM and Anderson WF (2006). Patterns of cancer incidence, mortality, and prevalence across five continents: defining priorities to reduce cancer disparities in different geographic regions of the world. J. Clin. Oncol. 24: 2137-2150.http://dx.doi.org/10.1200/JCO.2005.05.2308 
Kammerer S, Roth RB, Reneland R, Marnellos G, et al. (2004). Large-scale association study identifies ICAM gene region as breast and prostate cancer susceptibility locus. Cancer Res. 64: 8906-8910.http://dx.doi.org/10.1158/0008-5472.CAN$\underline{04-1788}$

Kuo WH, Huang CY, Fu CK, Hsieh YH, et al. (2014). Effects of interleukin-10 polymorphisms and smoking on the risk of gastric cancer in Taiwan. In Vivo 28: 967-971.

Landi S, Moreno V, Gioia-Patricola L, Guino E, et al.; Bellvitge Colorectal Cancer Study Group (2003). Association of common polymorphisms in inflammatory genes interleukin (IL)6, IL8, tumor necrosis factor a, NFKB1, and peroxisome proliferatoractivated receptor gamma with colorectal cancer. Cancer Res. 63: 3560-3566.

Li C, Tong W, Liu B, Zhang A, et al. (2014). The $-1082 A>G$ polymorphism in promoter region of interleukin-10 and risk of digestive cancer: a meta-analysis. Sci. Rep. 4: 5335.

Litovkin KV, Domenyuk VP, Bubnov VV and Zaporozhan VN (2007). Interleukin-6 -174G/C polymorphism in breast cancer and uterine leiomyoma patients: a population-based case control study. Exp. Oncol. 29: 295-298.

Mocellin S, Marincola F, Rossi CR, Nitti D, et al. (2004). The multifaceted relationship between IL-10 and adaptive immunity: putting together the pieces of a puzzle. Cytokine Growth Factor Rev. 15: 61-76.http://dx.doi.org/10.1016/j. cytogfr.2003.11.001

Pooja S, Chaudhary P, Nayak LV, Rajender S, et al. (2012). Polymorphic variations in IL-1 $\beta$, IL-6 and IL-10 genes, their circulating serum levels and breast cancer risk in Indian women. Cytokine 60: 122-128.http://dx.doi.org/10.1016/j. cyto.2012.06.241

Smith KC, Bateman AC, Fussell HM and Howell WM (2004). Cytokine gene polymorphisms and breast cancer susceptibility and prognosis. Eur. J. Immunogenet. 31: 167-173.http://dx.doi.org/10.1111/j.1365-2370.2004.00462.x

Smyth MJ, Cretney E, Kershaw MH and Hayakawa Y (2004). Cytokines in cancer immunity and immunotherapy. Immunol. Rev. 202: 275-293.http://dx.doi.org/10.1111/j.0105-2896.2004.00199.x

Talaat RM, Ashour ME, Bassyouni IH and Raouf AA (2014). Polymorphisms of interleukin 6 and interleukin 10 in Egyptian people with Behcet's disease. Immunobiology 219: 573-582.http://dx.doi.org/10.1016/j.imbio.2014.03.004

Venetsanakos E, Beckman I, Bradley J and Skinner JM (1997). High incidence of interleukin 10 mRNA but not interleukin 2 mRNA detected in human breast tumours. Br. J. Cancer 75: 1826-1830.http://dx.doi.org/10.1038/bjc.1997.311

Vickers MA, Green FR, Terry C, Mayosi BM, et al. (2002). Genotype at a promoter polymorphism of the interleukin-6 gene is associated with baseline levels of plasma C-reactive protein. Cardiovasc. Res. 53: 1029-1034.http://dx.doi.org/10.1016/ $\underline{\text { S0008-6363(01)00534-X }}$

Yang M, Li C and Li M (2014). Association of interleukin-6 (-174 G/C) polymorphism with the prostate cancer risk: A metaanalysis. Biomed. Rep. 2: 637-643.

Yeh KY, Li YY, Hsieh LL, Chen JR, et al. (2010). The -174 G/C polymorphism in interleukin-6 (IL-6) promoter region is associated with serum IL-6 and carcinoembryonic antigen levels in patients with colorectal cancers in Taiwan. J. Clin. Immunol. 30: 53-59.http://dx.doi.org/10.1007/s10875-009-9324-6 